DE ECONOMIST 158, NO. 2, 2010

\title{
HOW A REDUCTION OF STANDARD WORKING HOURS AFFECTS EMPLOYMENT DYNAMICS
}

BY

PEDRO S. RAPOSO* AND JAN C. VAN OURS ${ }^{* *, * * *, * * * *}$

\begin{abstract}
Summary
December 1, 1996 a new law was implemented in Portugal to gradually reduce the standard workweek from 44 to $40 \mathrm{~h}$. We study how this mandatory reduction affected employment through job creation and job destruction. There was considerable regional, sectoral and firm-size variation in the share of workers who were affected by the working hours reduction. We exploit this variation to assess the impact of the workweek reduction. We find evidence that the working hours reduction had a positive effect on employment through a fall in job destruction.
\end{abstract}

Key words: workweek reduction, policy reform, employment dynamics

JEL Code(s): J22, J63, J81

\section{INTRODUCTION}

Employment effects of working hours reductions are not easy to establish empirically and indeed previous studies examine the impact of working hours reduction on the employment position of individuals but do not address overall employment effects. The main reason for the lack of evidence on the overall employment effects concerns the lack of information about the number of workers that find new jobs through the birth of firms. At the individual level it is rather straightforward to use workers working above the "new" standard hours before the policy change as the treatment group and workers working at or below the "new" standard hours before the policy change as a

* CentER, Department of Economics, Tilburg University, Tilburg, The Netherlands, email: P.M.SantosRaposo@uvt.nl

** Corresponding author: CentER, Department of Economics, Tilburg University, Tilburg, The Netherlands, email: vanours@uvt.nl

*** Department of Economics, University of Melbourne, Parkville, VIC, Australia

**** CEPR, London, UK

We are grateful to the Ministry of Employment, Statistics Department, for access to the QP data. We thank two anonymous referees for helpful comments on a previous version of the paper. Pedro S. Raposo gratefully acknowledges financial support by the Portuguese Foundation of Science and Technology, FCT [SFRH/BD/21906/2005]. 
control group. However, establishing the overall employment effects is a nontrivial exercise as there is no control group for firms that were created after the introduction of the policy change. In this paper we attempt to establish the comprehensive employment effects by performing an analysis at the level of well defined labor markets.

In Portugal December 1, 1996 a new law was implemented aiming to gradually reduce the standard workweek from 44 to $40 \mathrm{~h}$. The main reason for implementing this mandatory reduction of working hours was to speed up convergence of Portuguese traditionally long hours of work to the European average. In a companion paper we investigated how the Portuguese working time reduction affected individual jobs (Raposo and Van Ours 2010). In the current paper we investigate the overall employment effects. There was considerable regional, sectoral and firm-size variation in the share of workers who were affected by the working hours reduction. If the reduction in working hours affected employment it is likely to have had a bigger impact when the share of affected workers was high. Therefore, we can exploit the variation across labor markets to assess the impact of the workweek reduction. To do so we perform an analysis on the level of labor markets defined by industry, region and firm size. This aggregate approach allows us to study job creation and job destruction as well as worker accessions and separations and thus the net employment effects. ${ }^{1}$

The remainder of the paper is organized as follows. Section 2 discusses the reduction of the workweek in Portugal. Section 3 discusses the economics of working hours both from a theoretical and an empirical point of view. Section 4 presents our data. In Sect. 5 we report the results of our empirical analysis. Section 6 concludes.

\section{THE REDUCTION OF THE WORKWEEK IN PORTUGAL}

In Portugal, the 1990s were a decade with low unemployment rates; approximately 3-4\% points below the EU-15 average. Portugal is considered to have a regulated and centralized labor market, with minimum wages, strong employment protection, and collective bargaining widely applied (Cardoso 2006). The Portuguese government defines by law the limits to the standard number of hours of work per week.

In December 1996, a new law was introduced with the aim of reducing the standard workweek from 44 to $40 \mathrm{~h}$. The law was not passed as a tool to create jobs and reduce unemployment but was introduced because the newlyelected government wanted to speed up the convergence of Portuguese traditionally long hours of work to the European average (Varejão 2005).

1 In a similar set-up Stewart (2002) exploits regional variation in wages across the UK to establish the impact of the introduction of the minimum wage. 
The new law implied first, by 1st December 1996, all workweeks above $42 \mathrm{~h}$ should be reduced by $2 \mathrm{~h}$; workweeks below $42 \mathrm{~h}$ but above $40 \mathrm{~h}$ should meet the new standard of $40 \mathrm{~h}$ per week. Second, by 1st December 1997, all workweeks still above $40 \mathrm{~h}$ should meet the standard.

In order to compensate firms for the reduction in working hours the new law introduced some flexibility. The reduction was implemented taking into account that the standard workweek could be defined on a 4 months average. Furthermore, the maximum number of daily working hours could be increased by 2 provided that it did not exceed $10 \mathrm{~h}$ per day and $50 \mathrm{~h}$ per week.

\section{ECONOMICS OF WORKING HOURS REDUCTION}

\subsection{Theory}

Shorter working hours may be introduced through mandatory laws or may be the result of bargaining between unions and firms (See also Boeri and Van Ours 2008). A reduction of the workweek can be introduced for several reasons. Shorter working hours may increase the standards of living or it may be according to preferences of workers. Sometimes work sharing, i.e. reductions in the length of the working week leading to more jobs, is motivated as a tool to reduce unemployment. The idea is that if working time per worker is reduced then employment, counted as the number of workers will increase. This of course is only true if the reduction of the working hours does not affect labor demand too much - i.e. if there is a 'lump of labor' which can simply be redistributed at no costs. In a competitive labor market it may be that workers want to organize a reduction in working hours because this would increase their marginal product of labor (Marimon and Zillibotti 2000). The mandatory reduction of working hours would give the workers market power so they could increase their wage. Of course, individual workers would like to deviate from the agreement and work longer hours at the higher wage - in the same way as producers have an incentive to deviate from a cartel agreement. Another reason for a mandatory reduction of working hours arises when employers have monopsony power. Manning (2003) argues that in a monopsony not only the wage rate is less than the value of marginal product but the firm can also induce the worker to work more than would be optimal for the worker given the monopsony wage. In the same way as a minimum wage can be welfare improving in case of a monopsony, working hours reduction can be welfare improving.

Whatever the reason for a working hours reduction, the question arises if there is an employment effect. From a theoretical point of view it is not obvious whether working hours reductions will increase or reduce employment. Lets assume that technology is represented by a Cobb-Douglas production function $Y=H^{\gamma} N$ where $0<\gamma<1$, which implies that output 
is proportional to the number of workers while due to physical constraints there are diminishing returns to hours of work in production. Labor costs per worker are given by

$$
W=b+w H+\theta w\left(H-H_{s}\right) d
$$

where $H_{s}$ is the standard working hours, $d$ is a dummy variable that has a value of 1 if $H \geq H_{s}$ and a value of zero otherwise, $b$ represents the fixed costs per worker that are independent of working hours. These are mainly the costs of hiring, firing as well as training costs, $w$ is the hourly wage rate, $\theta(\theta>0)$ is the overtime premium. Assuming a competitive product market with price equal to 1 , the expression for the profits of the firm is given by

$$
\Pi(H, N)=H^{\gamma} N-W N
$$

The firm chooses $H$ and $N$ such that profits are maximized. The first order conditions for a maximum are:

$$
\begin{aligned}
& \frac{\partial \Pi}{\partial N}=H^{\gamma}-b-w H_{s}-\theta w\left(H-H_{s}\right) d=0 \\
& \frac{\partial \Pi}{\partial H}=\gamma H^{\gamma-1} N-w(1+\theta d) N=0
\end{aligned}
$$

Solving these two equations we obtain the optimal number of hours as:

$$
H^{*}=\frac{\gamma\left(b-\theta w H_{s} d\right)}{(1-\gamma) w(1+\theta d)}
$$

When the standard number of hours is reduced the employment effects depend on the new optimal number of hours $\left(H^{* *}\right)$. We distinguish three situations:

1. If $H^{* *}<H_{s}^{\text {new }}, \frac{\partial N}{\partial H_{s}}=\frac{\partial H}{\partial H_{s}}=0$.

2. If $H_{s}^{\text {new }} \leq H^{* *} \leq H_{s}^{\text {old }}, \frac{\partial N}{\partial H_{s}}=\frac{\partial H}{\partial H_{s}}=0$ or $\frac{\partial N}{\partial H_{s}}<0, \frac{\partial H}{\partial H_{s}}>0$.

3. If $H^{* *}>H_{s}^{\text {old }}$, then $\frac{\partial N}{\partial H_{s}}>0, \frac{\partial H}{\partial H_{s}}<0$.

Situation 1 occurs when the optimal number of hours is below the new standard; situation 2 occurs when the optimal hours are higher than the new standard but lower than the old standard and situation 3 occurs when the optimal number of hours is higher than the old standard.

Under situation 1 the optimal number of hours is independent of the standard number of hours. ${ }^{2}$ Therefore the change in the standard number of hours does not affect the level of employment. If the new optimal hours

2 Note that if in Eq. 5 there are no overtime hours $d=0$, in which case the optimal number of working hours is given by $H^{*}=\frac{b \gamma}{w(1-\gamma)}$. 
choice is in situation 2 the employment effects depend on the overtime premium and the fixed labor costs (see also Calmfors and Hoel 1988). For illustrative purposes consider the following example. A firm has $N$ workers working $42 \mathrm{~h}$ at a wage $w$ with fixed costs $b$. So total wage costs are $N *(42 *$ $w+b)$. Assume that as in Portugal, the standard workweek is reduced from 44 to $40 \mathrm{~h}$ while the total labor input is unaffected. Now the firm has to choose between attracting new workers in which case the total wage costs become $\frac{42}{40} N *(w * 40+b)$. Or, the firm doesn't do anything, which implies that it has to pay for overtime work for which premium is $50 \%$ (as is the case in Portugal for the first overtime hour). Then, the total wage costs become $N *(40 * w+2 * 1.5 * w+b)$. It is straightforward to see that the firm will expand its workforce if $b<20 * w$ while it will leave hours and employment unaffected if $b>20 * w$. Note that this threshold is quite high as it is equivalent to half of the weekly wage. This makes it very likely that firms will follow the first strategy, i.e. reduce working hours and expand the workforce.

In situation 3, workers already worked overtime and the hours reduction causes employment to fall. This is because the hours reduction has made the employment of a worker more expensive while the price of marginal hours has not changed. Therefore, firms will reduce the production factor which became more expensive (employees) and will use more of the input of which price has not changed (hours). Heterogenous firms may react differently to a reduction in standard working hours, which makes it difficult to predict the economy-wide employment effects.

\subsection{Empirical Findings}

Empirical studies find little evidence of working hours reductions leading to the creation of jobs. For Germany, Hunt (1999) finds no positive employment effects of the gradual working time reduction that occurred in the 1980s and 1990s. Andrews et al. (2005) also find no evidence of positive employment effects of working hours reduction in Germany. For France, Crépon and Kramarz (2002) study the 1982 reduction of the workweek in France from 40 to $39 \mathrm{~h}$ finding that it didn't create jobs but increased unemployment. Estevão and Sá (2008) study the further reduction of the workweek in France from 39 to $35 \mathrm{~h}$ in 2000-2002. They find an increase in labor turnover but no effect on aggregate employment. Skuterud (2007) presents an analysis of the Canadian province of Quebec where the standard workweek was gradually reduced from 44 to $40 \mathrm{~h}$ concluding that the policy failed to raise employment. Varejão (2005) investigates the effects of a 1996 working time reduction in Portugal using establishment level data and finding that firms' reaction to the policy is affected by the presence of minimum wage earners and the use of overtime hours. Chemin and Wasmer (2009) explore geographic disparities to study the 1998-2000 35-h reform in France. They use the historical difference 
TABLE 1 - MEANS OF VARIABLES (ANNUAL PERCENTAGES)

\begin{tabular}{lrcrr}
\hline & $1994-1995$ & $1995-1996$ & $1996-1997$ & $1996-1998$ \\
\hline$\Delta e$ & 3.9 & 3.7 & 6.6 & 5.2 \\
JC & 18.7 & 18.6 & 20.4 & 19.4 \\
JD & 14.8 & 14.9 & 13.8 & 14.2 \\
WA & 37.1 & 36.6 & 38.6 & 37.5 \\
WS & 33.1 & 32.9 & 32.2 & 32.5 \\
\hline
\end{tabular}

of the region Alsace-Moselle as control group finding no significant impact of the 35-h reform on employment growth. Raposo and Van Ours (2010) analyze the effect of the Portuguese working time reduction on working hours, overtime hours, hourly wages, monthly earnings and individual job loss. This study finds that for workers who were affected by the new law working hours decreased, while hourly wages increased, keeping monthly earnings approximately constant. Furthermore, the working hours reduction reduced the job loss of workers directly affected. Finally, overtime hours hardly changed. In terms of our theoretical framework this implies that situation 2 is the most likely situation: the reduction in standard hours reduced actual hours. Thus, it seems likely that firms expanded their workforce. Sánchez (2009) studying the 2001 reduction of standard weekly working hours from 48 to $45 \mathrm{~h}$ in Chile finds that this did not have positive or negative employment effects.

\section{DATA}

We use a longitudinal data set matching firms and workers in the Portuguese economy, called Quadros de Pessoal (QP — "Lists of Personnel"). The Quadros de Pessoal data are collected annually by the Ministry of Employment through an inquiry that every establishment with wage-earners is legally obliged to fill in. Reported data cover all the personnel working for the establishment in a reference week in October. Every year QP gather information for more than two hundred thousand firms and two million workers (see Cardoso 2006) for more details). Our data cover the period 1994 until 1998. In order to estimate the impact of the reduction in hours on the overall level of employment we aggregate the firms to the level of labor markets defined by industry (seven categories), region (four categories) and size of the firm (three categories). Thus, we perform our analysis at the level of 84 labor markets. ${ }^{3}$ Table 1 shows the means of the variables we use in the analysis.

3 For some of these labor markets we didn't use information about all years. We removed some outliers, where the change in job creation rate and employment growth was strongly negative. 
We define job and worker flows as usual (Davis and Haltiwanger 1999). We denote the level of employment at firm $j$ in period $t$ as $e_{j t}$; the average number of employees at the start and the end of the period. We denote the change of employment at firm $j$ during period $t$ as $\Delta e_{j t}$; the change is calculated as the difference between the number of workers at the end of the period and the number of workers at the beginning of the period. The job destruction rate (JD) in period $t$ in the universe of firms $S$ is specified as:

$$
J D_{t}=\sum_{j \in S_{t}^{-}}\left(\left|\Delta e_{j t}\right|\right) / \sum_{j \in S_{t}} e_{j t}
$$

where $S_{t}^{-}$represents the subset of firms with $\Delta e_{j t}<0$. In the same way job creation rate $(\mathrm{JC})$ is defined as:

$$
J C_{t}=\sum_{j \in S_{t}^{+}}\left(\Delta e_{j t}\right) / \sum_{j \in S_{t}} e_{j t}
$$

where $S_{t}^{+}$represents the subset of firms with $\Delta e_{j t}>0$. These measures of job flows underestimate the true values of gross job destruction and creation. Even if at the level of an individual firm employment change equals zero there might be some job creation and job destruction going on. With heterogeneous workers, jobs and firms making the distinction between job and worker flows is fundamental.

If $F$ is the number of workers that left the firm in a particular period, and $H$ denotes the number of workers that entered the firm in that period, worker separations (WS) in period $t$ in the universe of firms $S$ is defined as:

$$
W S_{t}=\sum_{j \in S_{t}}\left(F_{j t}\right) / \sum_{j \in S_{t}} e_{j t}
$$

and worker accessions (WA) in period $t$ in the universe of all firms $S$ equals:

$$
W A_{t}=\sum_{j \in S_{t}}\left(H_{j t}\right) / \sum_{j \in S_{t}} e_{j t}
$$

By definition, it holds that:

$$
J C_{t}-J D_{t}=W A_{t}-W S_{t}=\Delta e_{t}
$$

A surviving firm is a firm that is reported in our data in both, 1996 and in the current year $(t)$. The birth of a new firm is reported if it is the first time this firm is reported in our data. We consider there exists a firm closure if a firm is reported as having gone out of business at time $t$ if that year is the first year it fails to report.

Table 2 shows that total job creation in the period October 1994-1995 was $17 \%$ while in the year thereafter it was $15 \%$. Job creation increased 
TABLE 2 - JOB fLOWS AND WORKER FLOWS; 1994-1998

\begin{tabular}{|c|c|c|c|c|c|c|c|c|c|}
\hline & $\begin{array}{l}\text { Firm } \\
\text { new } \\
(1)\end{array}$ & $\begin{array}{l}\text { Firm } \\
\text { expansion } \\
\text { (2) }\end{array}$ & $\begin{array}{l}\text { Firm } \\
\text { contraction } \\
\text { (3) }\end{array}$ & $\begin{array}{l}\text { Firm } \\
\text { closure } \\
(4)\end{array}$ & $\begin{array}{l}\text { Total job } \\
\text { creation } \\
(1+2)\end{array}$ & $\begin{array}{l}\text { Total job } \\
\text { destruction } \\
(3+4)\end{array}$ & $\begin{array}{l}\text { Net } \\
\text { employment }\end{array}$ & $\begin{array}{l}\text { Worker } \\
\text { accession } \\
(5)\end{array}$ & $\begin{array}{l}\text { Worker } \\
\text { separation } \\
\text { (6) }\end{array}$ \\
\hline 1994-1995 & 8 & 9 & 6 & 7 & 17 & 14 & 3 & 33 & 30 \\
\hline 1995-1996 & 7 & 8 & 7 & 8 & 15 & 15 & 0 & 31 & 31 \\
\hline 1996-1997 & 10 & 9 & 6 & 7 & 18 & 13 & 5 & 35 & 30 \\
\hline 1997-1998 & 9 & 9 & 6 & 9 & 18 & 15 & 3 & 34 & 31 \\
\hline
\end{tabular}

Note: Change in employment between two subsequent dates as percentage of the average employment at these two dates; October data

to $18 \%$ in the period October 1996-1997 and October 1997-1998. On the other hand total job destruction in the period October 1994-1995 and October 1995-1996 was around 14-15\% while it decreased to $13 \%$ in the period October 1996-1997. In the year thereafter job destruction increased again to 15\%. Thus, immediately after the policy was implemented in December 1996 job creation increased and job destruction decreased causing net employment to increase $5 \%$. In the year thereafter job creation was constant while job destruction increased somewhat, causing employment to grow 3\%. Of course, these developments in job flows and worker flows may have been affected by the working hours reduction, but they may also be influenced by changes in the Portuguese economy. In an economy known to be characterized by very high levels of firm creation and firm closures (Mata and Portugal 1994) it is not strange to see that after 1996, job creation increased mainly through new firms. The main reason behind the decrease of the job destruction is not so clear, firm closure or firm contraction. The last two columns in Table 2 show that worker accessions fluctuate more than worker separations. It is also clear that worker turnover rates are high. Every year about one third of all Portuguese workers leave their job and find a new job. ${ }^{4}$

\section{EMPIRICAL ANALYSIS}

\subsection{Set-Up of the Analysis}

By using market level data we can take the creation of new firms in a particular market into account because they are part of employment creation in that market. The way these labor markets are affected by the working hours reduction depends on how many workers are affected within these labor mar-

4 Blanchard and Portugal (2001) argue that those high turnover rates in Portugal are related to the small size of firms in Portugal. 


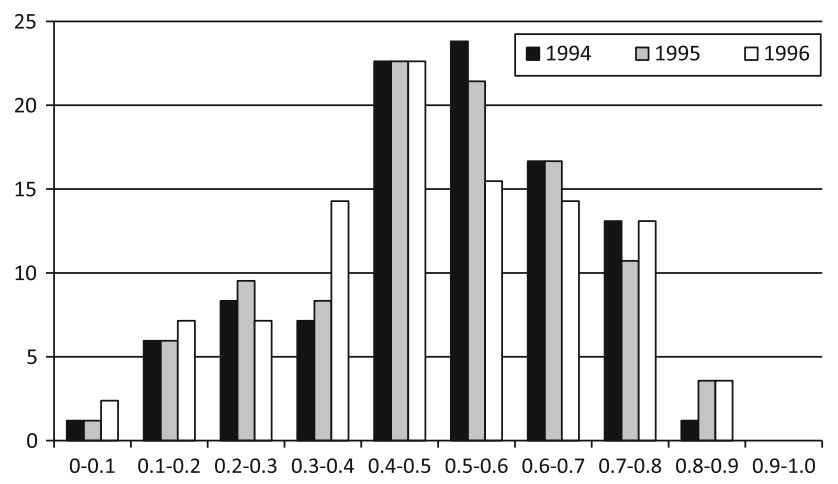

Figure 1 - Market level distribution of the share of workers working more than $40 \mathrm{~h}$ per week; October 1994-1996 (percentages)

kets. ${ }^{5}$ As a definition of policy intensity we use a variable $n$, defined as the share of affected workers - in each of the 84 labor markets-working more than $40 \mathrm{~h}$ at the relevant October dates. The distribution of $n$ in the period October 1994-October 1996, shortly before the working hours reduction, is presented in Fig. 1. Clearly the policy intensity varies a lot between the different labor markets. Over time there are some changes in the distribution but by and large the distribution of $n$ in various years looks very much alike.

To analyze the year 1 effects of the working week reduction in labor market $k$ represented by industry, region, size we estimate the following equation:

$$
y_{k t}=\alpha_{t}+\alpha_{k}+\beta n_{k t}+\delta n_{k t} \cdot d_{p}+\epsilon_{k t}
$$

The dependent variables are job creation rate (JC), job destruction rate (JD), worker accession rate (WA) and worker separation rate (WS) and change in employment $(\Delta e)$ from $t$ to $t+1$, where $t$ runs from October 1994 to October 1996. Furthermore, the $\alpha_{t}$ represents calendar time fixed effects, the $\alpha_{k}$ represent time-invariant labor market fixed effects, $d_{p}$ represents a dummy variable for the post reform period, and $n$ represents the share of individuals that worked more than $40 \mathrm{~h}$ in October of year $t$. The main parameter of interest is $\delta$, representing the treatment effect. Finally, $\epsilon$ represents an error term.

5 Obviously, the hourly wage may have been affected by the reduction of standard working hours. However, this doesn't affect our reduced form analysis, in which we relate the change in standard working hours to the employment effect without attempting to distinguish between the various determinants of this change. 


\subsection{Exploratory Analysis}

To give an idea about the relationship between the share of workers working more than $40 \mathrm{~h}$ per week and employment growth, job creation and job destruction Fig. 2 presents an exploratory analysis. The horizontal axis shows the share of workers working more than $40 \mathrm{~h}$ per week in October 1996, shortly before the mandatory reduction in the standard working week was implemented. The vertical axis shows changes in the period October 1996October 1997 in employment growth (panel $a$ ), job creation (panel $b$ ) and job destruction (panel $c$ ).

As shown in panel $a$ of Fig. 2 the higher share of $40+\mathrm{h}$ workers, the higher the change in employment growth. The slope of the straight lines in Fig. 2 represent an estimate for $\delta{ }^{6}$ Indeed, the slope is positive in panel $a$ indicating that the larger the share of workers involved in the reduction of the standard workweek the higher employment growth.

Panel $b$ shows that there is no such relationship with job creation, while from panel $c$ it is clear that job destruction is affected by the reduction of the standard workweek: the larger the share of workers involved in the reduction of the standard workweek the lower the change in job destruction.

\subsection{Parameter Estimates}

The parameter estimates for $\delta$ from Eq. 11 estimated over the period 1994 1997 are presented in the first column of Table 3. As shown the change in employment is significantly affected. The higher $n$, the higher employment growth. Conditional on the other characteristics of the labor market, an average labor market with an $n$ of 0.5 experiences an employment growth of almost 5\%. As shown, job creation and worker accessions are not affected by the reduction of the standard workweek. But, job destruction and workers separations are negatively affected. Apparently, labor markets confronted with a reduction of the standard workweek reduce job destruction and thus increase employment. This would be in line with predictions from the theoretical model. Limiting the estimation period to 1995-1997 hardly affects the parameter estimates (column 2).

6 Note that if we take first differences of Eq. 11 over the period 1995-1996 we find:

$$
\Delta y_{k, 95-96}=\alpha_{96}-\alpha_{95}+\beta\left(n_{k, 96}-n_{k, 95}\right)+\delta n_{k, 96}+\epsilon_{k, 96}-\epsilon_{k, 95}
$$

such that if $n$ didn't change too much between 1995 and 1996 we find:

$$
\Delta y_{k, 95-96} \approx \alpha^{*}+\delta n_{k, 96}+\epsilon^{*}
$$

In a linear regression we find for $\delta$ (absolute $t$-statistics based on robust standard errors): panel $a$ : 0.090 (1.8), panel $b: 0.017$ (0.6), panel $c:-0.074(2.2)$. 

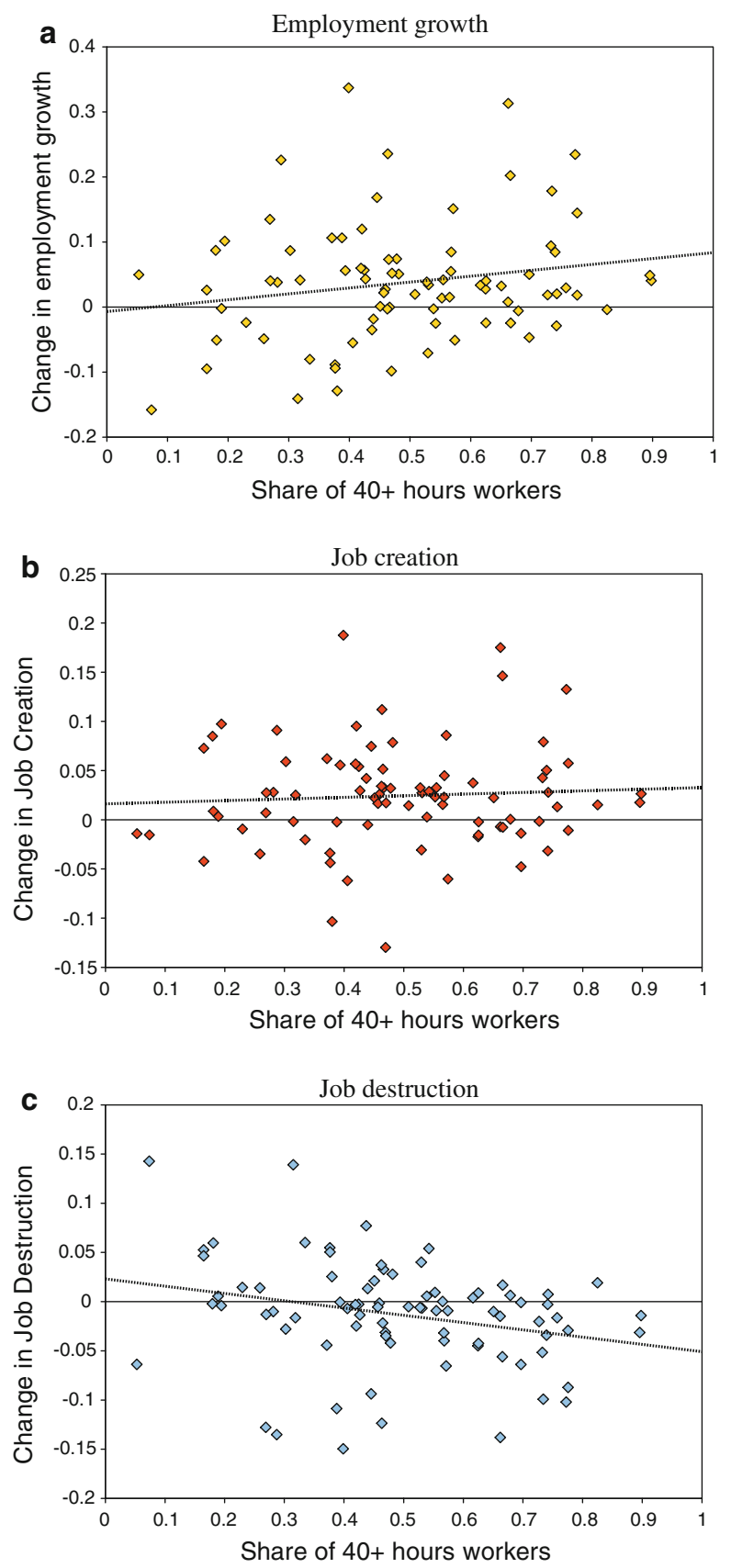

Figure 2 - Changes in employment growth, job creation and job destruction; 1996-1997. 
TABLE 3 - BASELINE ESTIMATES

\begin{tabular}{|c|c|c|c|c|}
\hline & \multicolumn{2}{|l|}{1 Year effect } & \multicolumn{2}{|l|}{2 Years effect } \\
\hline & 1994-1997 & 1995-1997 & 1994-1998 & 1995-1998 \\
\hline & (1) & (2) & (3) & (4) \\
\hline$\Delta e$ & $0.097(2.1)^{* *}$ & $0.125(2.2)^{* *}$ & $0.091(1.8)^{*}$ & $0.110(1.8)^{*}$ \\
\hline $\mathrm{JC}$ & $0.013(0.5)$ & $0.012(0.4)$ & $0.006(0.2)$ & $-0.002(0.1)$ \\
\hline JD & $-0.084(3.1)^{* *}$ & $-0.113(3.3)^{* *}$ & $-0.085(2.4)^{* *}$ & $-0.113(2.5)^{* *}$ \\
\hline WA & $0.020(0.6)$ & $0.030(0.9)$ & $-0.004(0.1)$ & $-0.007(0.2)$ \\
\hline WS & $-0.082(2.3)^{* *}$ & $-0.096(2.1)^{* *}$ & $-0.097(2.2)^{* *}$ & $-0.117(2.2)^{* *}$ \\
\hline Observations & 249 & 165 & 250 & 165 \\
\hline Labor markets & 84 & 84 & 84 & 84 \\
\hline
\end{tabular}

Note: All estimates also have the share of $40+\mathrm{h}$ workers $(n)$ as explanatory variable in addition to labor market fixed effects (84) and calendar period fixed effects (3); absolute $t$-statistics based on robust (cluster) standard errors in parentheses (Bertrand et al. 2004); a **/* indicates that the coefficient is different from zero at a $5 \% / 10 \%$ level of significance

Replacing $y_{k t}$ for $t=1996$ in Eq. 11 by the averages for the period 19961998 we also estimated the year 2 effects of the working hours reduction. The parameter estimates are presented in the third and fourth column of Table 3. The results are very much the same as before.

The market level analysis allows us to make a distinction between worker accessions to new firms and worker accessions to firms that survive. Similarly, we can make a distinction between worker separations from firm closures and worker separations from surviving firms. Table 4 also shows how the working hours reductions affects the flow of workers to and from these different types of firms. The working hours reduction mainly affects worker flows to new firms and from firm closures. Conditional on the other characteristics of the labor market, firms being born and dying on an average labor market with an $n$ of 0.5 experience an employment growth of almost $5 \%$ after 1 year where half of this effect comes from worker separations and half comes from worker accessions. After 2 years the effect on net employment is positive but smaller $(3.5 \%)$ and it comes mainly from the reduction of worker separations. The effects to and from surviving firms are much smaller after 1 year but after 2 years the effects are very similar.

We performed two types of sensitivity analysis relating to our measure of policy intensity and relating to our definition of labor market. In our baseline estimates our policy intensity parameter is measured by the share of workers working more than $40 \mathrm{~h}$. As an alternative policy intensity indicator we used the per worker average number of hours in excess of $40 \mathrm{~h}$. In our baseline estimates we distinguish labor markets according to industry, region and 
TABLE 4 - SENSITIVITY ANALYSIS; DISTINGUISHING BETWEEN SURVIVING FIRMS AND FIRMS BEING BORN/DYING

\begin{tabular}{|c|c|c|c|c|}
\hline & \multicolumn{2}{|l|}{1 Year effect } & \multicolumn{2}{|l|}{2 Years effect } \\
\hline & 1994-1997 & 1995-1997 & 1994-1998 & 1995-1998 \\
\hline & (1) & (2) & (3) & (4) \\
\hline \multicolumn{5}{|c|}{ Firms being born and dying } \\
\hline$\Delta e$ & $0.089(2.6)^{* *}$ & $0.112(2.6)^{* *}$ & $0.061(1.8)^{*}$ & $0.083(2.1)^{* *}$ \\
\hline WA & $0.045(1.9)^{*}$ & $0.048(1.8)^{*}$ & $0.019(0.9)$ & $0.019(0.8)$ \\
\hline WS & $-0.044(2.7)^{* *}$ & $-0.064(2.7)^{* *}$ & $-0.042(1.9)^{*}$ & $-0.064(2.2)^{* *}$ \\
\hline \multicolumn{5}{|l|}{ Surviving firms } \\
\hline$\Delta e$ & $0.008(0.3)$ & $0.013(0.4)$ & $0.030(1.1)$ & $0.027(0.8)$ \\
\hline WA & $-0.025(0.9)$ & $-0.019(0.7)$ & $-0.024(0.8)$ & $-0.026(0.8)$ \\
\hline WS & $-0.038(1.4)$ & $-0.032(1.0)$ & $-0.055(2.1)^{* *}$ & $-0.052(1.7)^{*}$ \\
\hline Observations & 249 & 165 & 250 & 165 \\
\hline Labor markets & 84 & 84 & 84 & 84 \\
\hline
\end{tabular}

Note: See footnote Table 3

firm size. As a sensitivity analysis we ignored the distinction by firm size. This reduces the number of labor markets from 84 to 28 . For both sensitivity analyses we find that the relevant parameter estimates are very much the same as before. From this, we conclude that our parameter estimates are quite robust.

\section{CONCLUSIONS}

Previous empirical studies suggest that reductions of standard working hours do not have positive employment effects. However, previous studies only measure partial employment effect while in our study we consider overall employment effects. We study the working hours reduction that was introduced in Portugal in 1996. In our analysis we exploit regional, sectoral and firm-size variation in the share of workers who were affected by the working hours reduction. A working hours reduction is likely to have had a bigger impact when the share of affected workers was high. To investigate this we perform an analysis on the level of labor markets defined by industry, region and firm size. We find evidence that the working hours reduction had a positive effect on employment through a fall in job destruction. The reduced labor costs didn't stimulate job creation which may have to do with the strict employment protection in Portugal. We can only speculate about the reason why reducing standard working hours in Portugal increased employment whereas in other countries no such effects occurred. Most likely, the increased flexibility in the use of the standard workweek made it easier to adjust the workforce at the 
intensive margin rather than at the extensive margin. To the extent that this reduced labor costs, job destruction was reduced, causing positive employment effects.

Open Access This article is distributed under the terms of the Creative Commons Attribution Noncommercial License which permits any noncommercial use, distribution, and reproduction in any medium, provided the original author(s) and source are credited.

\section{REFERENCES}

Andrews, M.J., T. Schank and R. Simmons (2005), 'Does Worksharing Work? Some Empirical Evidence from the IAB-Establishment Panel'. Scottish Journal of Political Economy, 52, pp. 141-176.

Bertrand, M., E. Duflo and S. Mullainathan (2004), 'How much Should We Trust Differences-inDifferences Estimates?' Quarterly Journal of Economics, 119, pp. 249-275.

Blanchard, O. and P. Portugal (2001), 'What Hides Behind an Unemployment Rate: Comparing Portuguese and U.S. labor markets'. American Economic Review, 91, pp. 187-207.

Boeri, T. and J.C. Van Ours (2008), The Economics of Imperfect Labor Markets, Princeton University Press.

Calmfors, L. and M. Hoel (1988), 'Worksharing and Overtime'. Scandinavian Journal of Economics, 90, pp. 45-62.

Cardoso, A.R. (2006), 'Wage Mobility: Do Institutions Make a Difference? A Replication Study Comparing Portugal and the UK'. Labour Economics, 13, pp. 387-404.

Chemin, M. and E. Wasmer (2009), 'Using Alsace-Moselle Local Laws to Build a Differencein-Differences Estimation Strategy of the Employment Effects of the 35-Hour Workweek Regulation in France. Journal of Labor Economics, 27, pp. 487-524.

Crépon, B. and F. Kramarz (2002), 'Employed 40 Hours or Not-Employed 39: Lessons from the 1982 Workweek Reduction in France'. Journal of Political Economy, 110, pp. 1355-1389.

Davis, S.J. and J. Haltiwanger (1999), 'Gross Job Flows'. in: O. Ashenfelter and D. Card (eds.), Handbook of Labor Economics, vol. 3, Amsterdam, Elsevier, pp. 2711-2805.

Estevão, M. and F. Sá (2008), 'The 35 Hour Workweek in France: Straightjacket or Welfare Improvement?' Economic Policy, 55, pp. 417-463.

Hunt, J. (1999), 'Has Work-Sharing Worked in Germany?' Quarterly Journal of Economics, 114, pp. $117-148$.

Manning, A. (2003), Monopsony in Motion: Imperfect Competition in Labor Markets, Princeton University Press.

Mata, J. and P. Portugal (1994), 'Life Duration of New Firms'. Journal of Industrial Economics, 42, pp. 227-245.

Marimon, R. and F. Zillibotti (2000), 'Employment and Distributional Effects of Restricting Working Time'. European Economic Review, 44, pp. 1291-1326.

Raposo, P. and J.C. Van Ours (2010), 'How Working Time Reduction Affects Jobs and Wages'. Economics Letters, 106, pp. 61-63. 
Sánchez, R. (2009), Do Reductions of Standard Hours Affect Employment Transitions? Evidence from Chile, mimeo, University of Warwick.

Skuterud, M. (2007), 'Identifying the Potential of Work-Sharing as a Job-Creation Strategy'. Journal of Labor Economics, 25, pp. 265-287.

Stewart, M. (2002), 'Estimating the impact of the minimum wage using geographical wage variation'. Oxford Bulletin of Economics and Statistics, 64, pp. 583-605.

Varejão, J. (2005), Work-Sharing Revisited—Lessons from a Natural Experiment, mimeo, Faculdade de Economia do Porto, Porto. 